\title{
Happiness and Memory: some sociological reflections
}

\author{
Sociological Research Online \\ For consideration for the Special Section on Happiness and Well-being
}

\begin{abstract}
This article seeks to consider, in an exploratory fashion, the relationship between happiness and memory. Both of these areas of investigation are relative newcomers to sociology, and have rarely, if at all, been studied in tandem. The article draws upon data from qualitative interviews with British adults that formed part of an empirical study of people's experiences and perceptions of happiness. In doing so, it suggests that people identify their memories and reflections on the past as sources of happiness in two interrelated ways. Firstly, people - particularly those of an older generation - make sense of life in the past as happier than that of the present. This is the case with regard to society in general as well as to their personal lives specifically. The 'past-situated social identities' of older people are considered in relation to this. Secondly, adults of a range of ages understand reminiscing about the past as something from which happiness or pleasure could be gained. Life course transitions, and the way in which adults make sense of and live through these, are key in the way in which people express nostalgia for, or idealization of the past. Reconnecting with the past can be regarded as a 'technology of the self', or a technique that people perform on their own minds, in order to enable themselves to feel happier. The article ends with a consideration of the implications of this for the ways in which happiness is theorized sociologically.
\end{abstract}

Keywords: Happiness, Memory, The Past 


\section{Introduction}

Traditionally viewed as individual, personal and private, happiness was once considered to be outside the remit of sociology, and only recently have sociologists started to recognize it as an area worthy of concern. Scholars across the social sciences over the past forty years or so have preoccupied themselves with the measurement and monitoring of happiness on a local, national or international level (see Easterlin 1974; Oswald 1997; Graham 2009 for example). Examinations of everyday experiences of happiness, however, continue to be absent from sociological inquiry, with only a small number of exceptions (for example, Hyman 2011, Cieslik 2013). It is this latter body of work that this article seeks to contribute to, by considering empirically the ways in which people draw happiness and pleasure from reflection on memories about the past. It demonstrates that the role of memory in people's experiences of happiness is a pertinent one.

One way in which the relationship between happiness and memory can be considered is through the two 'selves' proposed by behavioural economist Daniel Kahneman (2011): the 'experiencing self' and the 'remembering self'. Whilst this is not a sociological idea per se, this article proposes that it can make an important contribution to the sociological study of happiness and memory. Kahneman (2011) asserts that one's self is made up of the 'experiencing' and 'remembering' selves, and that the two are qualitatively different; the first is concerned with how one feels at the time of a given experience, and the second is concerned with how one remembers how they felt previously. This article thus asserts that both selves can experience happiness; that is, it can be expressed as a response to an event in the present or to a recollection of - or 'fantasy' about - the past.

Memory, like happiness, is also a relative newcomer to the sociological landscape. Once largely considered a psychological concern, it is now recognized by scholars as being fundamentally social, and work started to emerge on the topic in the latter half of the twentieth century. Sociologists such as Eviatar Zerubavel now understand that 'much of what we remember is actually filtered... through a process of interpretation that usually takes place within particular social surroundings.' (1996:285).

This paper brings these two areas together by considering empirically the ways in which people draw happiness and pleasure from reflection on memories about the past. It begins with a consideration of the two topics in turn; they are explored separately because at present, no other scholarly work has considered them in tandem. This is then followed by a brief description of the qualitative interview data that were employed in this article, and the study from which these came. Next is a presentation of the paper's findings, in which two distinct but interlinked themes, focused on how people reflect on the past, are highlighted: reflections on the ways in which people's lives were happier in the past (which was a particularly prominent theme amongst older people), and the idea that happiness can be gained from the act of reminiscing about the past (which was the case for people of a range of ages). The article then concludes with a consideration of the implications of its findings for sociological knowledge, particularly the sociological study of happiness, memory and time.

\section{Happiness and Sociology}


Happiness has been an area of concern across the humanities and social sciences for generations; philosophers such as Aristotle, Plato and Seneca have sought answers to questions about what the 'good life' consists of, and psychologists and economists have examined ways in which the happiness and well-being of populations can be monitored and maximized (for example, Seligman 2002; Easterlin 1974; Layard 2011). Despite this, sociologists have not followed suit until comparatively recently. One sociologist, Ruut Veenhoven (2011), has explored the ways in which improved living conditions can bring about a rise in happiness levels. Sociologists have also contributed to the rapidly growing body of work that is premised on measures of happiness at the local, national or international level (see Easterlin 2001; Layard 2011 for example). Across this area of work, happiness and well-being have been measured by scholars and governments in a range of ways. One widely adopted method is via the use of a survey question, which seeks to capture a person's overall happiness levels. It asks the following (or minor variations thereof): 'Taking all things together, how happy are you with your life as a whole these days?' Respondents are then asked to rate their happiness using a Likert scale of up to eleven points. Other methods have focused upon gathering more detailed responses; the Experience Sampling Method (ESM) (Csikszentmihalyi and Hunter 2003) involves participants being provided with a mobile device for a given period and responding to its 'beeps' at various points throughout each day, by providing answers to questions about how they are feeling at that moment. A less intrusive variant of this, known as the Day Reconstruction Method (DSM) (Kahneman et al. 2004) asks respondents to divide up the previous day into 'episodes', and then recall what they were doing and how they were feeling during each one. Whilst the survey method of measurement may yield information on different aspects of people's happiness to that of the latter two methods, what all three have in common is that they seek to capture people's evaluations of their lives in the present. This is a point central to this paper, and is one which I shall revisit in the article's Concluding Comments section.

This article makes a departure from this body of work, by seeking to understand particular aspects of the way in which happiness is experienced on an everyday level, and the meanings that individuals attribute to this. Explorations of this dimension of happiness seem to still be lacking in sociology, with only a small number of exceptions (see introduction). Nevertheless, what is important to bear in mind about this kind of work is that it highlights the social complexities surrounding experiences of happiness, and enables us to understand the ways in which happiness is an inherently social experience. If happiness and well-being are being measured and monitored, then research such as this offers us a deeper understanding of the processes that underpin what is being measured.

The temporal dimension of happiness - or its relationship with time and memory - is one such social complexity that can be taken into consideration. That is, people can gain happiness from reflection upon past experiences, as well as from present conditions, and happiness felt in the past can manifest itself in the here-and-now. Understanding how and why this happens is the main focus of this article. One way in which this relationship can be considered is through the two 'selves' proposed by behavioural economist Daniel Kahneman (2011): the 'experiencing self' and the 'remembering self', outlined in the article's introduction. Happiness that is drawn from reflecting on the past - which would be made sense of via the 'remembering self' - is different from happiness that is experienced 'in the moment' - made sense of via the 'experiencing self'. This dichotomy thus has implications both for this article specifically, and for the sociology of happiness more generally; these will be considered further in the final section of this article. 


\section{The Sociology of Memory}

Memory, like happiness, has not always been a popular area of sociological inquiry. Traditionally viewed as a topic best suited to the disciplines of History or Psychology, a body of sociological literature surrounding it has only emerged during the past thirty years. It is now recognized by scholars as being fundamentally social; as Schwartz asserts, memory 'orients our intentions, sets our moods, and enables us to act' (2000:251).

Much of the earlier sociological work on the topic was concerned with the concept of 'collective memory'. Pioneered by Maurice Halbwachs ([1926] 1950) and adopting a broadly Durkheimian perspective, this work focused on the role of shared memories common to groups, communities and societies in bringing about social solidarity and cohesion. It is the group context that influences and shapes individual remembrance. Other approaches to memory suggest that those in power in a given society or group help to determine what is remembered by its members, and indeed how it is remembered (Misztal 2003).

However, more recently it has also been suggested that there are less deterministic ways of examining social memory. Collective memories may be viewed as part of an ongoing process of negotiation (Misztal 2003). Individual and group identities change over time, and therefore memories must follow suit. They therefore undergo constant transformation. Furthermore, they can be construed as 'cultural products', affected by culture, but yet they are also the result of an individual's relation to their self and to the outside world (Prager 1998). It is in this way that Jeffrey Prager suggests that remembering is 'an active, interpretive process of a conscious mind situated in the world.' (1998: 215). Thus the ways in which we remember are intimately bound up with the ways in which we construct our selves, and how we see ourselves in relation to the wider world.

Central to this article is the idea that memories can be specific to generations, or groups of people born and living during approximately the same period, as each is likely to have unique and specific experiences (Misztal 2003; Mannheim 1972). Members of the same generation will be a part of the same historical and social circumstances, and it is these that can affect what and how different generations remember. Members of a generation may share common preferences, dispositions and a habitus, which also helps to illuminate the ways in which each may share common memories (Misztal 2003; Bourdieu 1977; Eyerman and Turner 1998).

The ways in which we articulate and come to terms with our memories can also be explored sociologically. Jedlowski (2001), for instance, suggests that our memories are inscribed within 'social frameworks' that consist of the categories through which the past is selected, ordered and understood. These frameworks are manifested when we articulate our memories through language and discourse and through narrative practices. Culturally dominant discourses or narratives are often drawn upon when past experiences are reflected upon, which also illustrates the fact that we articulate our memories in social ways. Zerubavel (1996) also contends that we can make use of material objects in our acts of remembrance. Museum exhibits, newspapers, television and radio broadcasts, photographs and videos can all be used to remind us of a memory or past event. 


\section{Happy Memories?}

As stated above, the main objective of this article is to illustrate sociologically the relationship between happiness and memory. Now that a brief examination of the key theoretical and empirical debates in each area has been undertaken, it is possible to see how they can be linked. With the exception of Kahneman's (2011) work, time and memory do not appear to be acknowledged in the existing literature on happiness. Similarly, happiness does not feature in sociological work on memory. However, the idea outlined above that memories can be articulated through language, discourse and narrative practices (Jedlowski 2001) is of key importance here, as it is also through such narratives or discourses that happiness can be articulated (Hyman 2011). It is the idea that people articulate and make sense of their happiness through reflection on past memories that is the central theme of this article. Questions can be raised, such as: why do people idealize the past? Why do people take pleasure in reminiscence?

In this vein, two themes are put forward: firstly, older people can position their happiness in the past by making sense of the past as happier than the present (and this is the case with regard to society in general and their own personal lives), and secondly, adults of all ages can gain happiness and pleasure from reminiscing about the past. These will each be explored further in later sections of this article.

\section{Data and Methods}

Qualitative interview data gathered as part of another empirical study undertaken by the author (Hyman 2011) have been drawn upon in this article. Interviews were initially conducted around the topic of people's experiences and perceptions of happiness. The sample comprised twenty-six adults from a variety of areas of the United Kingdom; they ranged in age from twenty-two to eighty. Members of the sample were recruited via two methods: some responded to an advertisement that was placed in a local London newspaper, and the remainder were gathered via a 'snowballing' method (that is, interviewees initially recruited via the advertisement put the researcher in touch with additional respondents whom were known to them). Thirteen males and thirteen females were interviewed. However, as this was an exploratory, qualitative study on the way in which people in Britain make sense of their experiences and perceptions of happiness, representativeness was not sought with regard to ethnic groups or social class backgrounds, and the majority of respondents were white and from middle-class backgrounds (with the exception of two black Caribbean participants and five who identified as working-class).

Respondents were not asked about their memories or past experiences per se. However, a large number of them acknowledged these when articulating their experiences and perceptions of happiness, either by recounting memorable past events in their accounts and narratives of happiness, or by identifying their memories and the act of reflection on the past as sources of happiness. What was particularly interesting here was that the majority of the participants aged sixty and above identified memories as key in their experiences of happiness, and many of them, as is shown below, made sense of their lives as happier in the past than in the present (this was so for four of the five respondents who were in this age group). This was not something highlighted by any younger respondents (aged below sixty), although some people in this age group did articulate 
feelings of happiness in relation to the act of reminiscing about the past. A discussion of the possible reasons for this disparity between groups is given later in the article.

It is thus in this article that some initial reflections on memory and happiness are presented. Exploring the relationship between happiness and memory through the analysis of qualitative interview data seemed more than appropriate as it is the meanings and ideas that people use to make sense of their social worlds that is under scrutiny here (Rubin and Rubin 2005). That is, how do people make sense of their experiences and ideas surrounding happiness, and how do their memories and recollections fit with this? How might they articulate their ideas through discourse or narrative practices (Jedlowski 2001)?

All study participants were assigned pseudonyms in order to preserve anonymity. The data were analysed using an inductive approach (Silverman 2005) and were then coded. All of the interview data containing references to remembering, the past and memories were extracted. Coding and generation of themes was done in three stages, similar to that outlined by Strauss and Corbin (1990). First, the data were examined and initial categories were created ('open coding'). Each category was then developed further into a 'theme', within which sub-categories emerged ('axial coding'). Lastly, the themes were integrated and drawn together ('selective coding'); this was then used as a framework for the two broad analytic themes were generated: people's lives were happier in the past, and happiness can be gained from reminiscing about the past. Each of these will now be examined in turn.

\section{Life was happier in the past}

The first notable theme is the idea that many people perceived their lives to have been happier in the past than in the present. This was the case both in terms of their understandings of society being a happier place in the past, and understanding their own personal lives as happier. This is something that was only talked about by the study's older respondents; all of those who expressed this idea are over sixty (and indeed, only one participant over sixty did not express it).

Laurence, for instance, explains how society has become 'materialistic' due to the increased exposure that we have to how other 'classes' live:

Interviewer: Do you think that people today are happier than in the past? (Laurence, 65): They should be [happier], but they don't seem to be. But I think mainly, it's because they're so... well, we've got very materialistic. They seem to think that will make us happy. You know, must have a third television, must have a second car, must have this, must have that. And if you think about it, you don't really need those things. [...] Class has also changed, you know, people used to be put into groups of classes which I'm glad is not there anymore. Not so much, anyway. You know, he knows his place, I know my place and everything else. So in a way that person was content with what they'd got in that class, but we're not anymore 'cos we've seen what the other side is, so we want it. We don't need it but we've got to have it. 
He outlines the way in which people are less happy today than in the past because of an increased greed for material goods. He acknowledges a modern 'malady of infinite aspiration' (Durkheim [1925] 1961) whereby people's heightened expectations in an increasingly affluent society have led, for some, to a feeling of discontentment or unhappiness.

Like Laurence, Eileen also mourns the loss of society's positive spirit:

(Eileen, 63): When I was young, there was camaraderie, with people... you helped one another then. People are not so ready now, to help one another. You know, there's a lot of jealousy, and I think jealousy is the worst thing. People are quick to run somebody else down, you know, they'd rather be talking about somebody else and running them down. And it just didn't seem like that when I was young, you know. You had good mates, you had your best friends and you were happy together. But there's all this... it is, it's just materialistic, with a lot of people. I won't say everybody, but a lot of people.

She acknowledges the way in which people have been more self-centred, and also suggests that this is due to a greed that has been instilled by material culture. Again, her perception that people are less able to be 'happy together' stems from a 'malady of infinite aspiration' (Durkheim [1925] 1961).

In a similar vein, Helen also claims that the world has changed:

Interviewer: Do you think that the idea of 'happiness' might have changed over time? (Helen, 77): Yes, it has. Because the world is now a different place... the youth of today make it... not so easy for children to play outside during the day. You don't know who's walking around... it's not like it used to be, it's different. You can't tell what this person's like, or that person's like, you know. And this is the difference, it has changed beyond all recognition. And the children, because of the laws of this country now about disciplining children, that you're not allowed to slap them and you're not allowed to do this or that, consequently, they're very rude to their parents...

She reflects upon the ways in which the world has become less safe, and acknowledges a societal breakdown of morals, a situation of anomie (see Durkheim [1897] 1951). She also makes implicit acknowledgment of an erosion of children's happiness, which she feels was a product of this.

The three quotes presented here all illustrate the ways in which most of the study's older respondents make sense of society in the past being happier than the present. What is interesting here is that these accounts pose a challenge to Ruut Veenhoven's (2011) claims that improved living conditions can raise levels of happiness. These older people perceive the quality of society and living conditions to have worsened (though this worsening may or may not have actually taken place), but yet - for Eileen and Laurence particularly - they can nevertheless reflect on the happiness that they felt in the past. Thus, it could be said here that people's subjective perceptions of living conditions are just as important as actual living conditions for understanding how people evaluate their lives.

Maureen reflected upon 'happy' memories from earlier parts of her own personal life, and explained that these periods were happier than her life at present. 


\section{Interviewer: Thinking about the course of your life, could you tell me about some 'happy' events that you've experienced, or 'happy' periods of your life?}

(Maureen, 80): Happy periods of my life... [pause]... yes, my granddaughter getting married, my children getting married, and my husband and I having good times in the old days when we used to go away and have a good laugh, on holiday. And also, when the children were young, their birthday parties and the games that we used to have in our garden. Those were good days, when we were young they were good days, but as one gets older, certain things happen and it does change. Nothing lasts forever. So when you do have something happy, you grab at it, you know. That's what life is all about. [...] it was the children when they were young that kept us happy. But once they grow up, they go their own way and certain things in life happen. Then it changes, nothing remains the same. And that's it really...

Maureen positions her happiness in the past by acknowledging that a period of her life that has now passed - that wherein her children were young - was a very happy time. The changes that have accompanied the ageing of her, her husband and children (which include health problems encountered by both her husband and one of her sons, and the death of her other son, described at another point during her interview) have prevented her from experiencing happiness in the same way since then.

The way in which she makes sense of this happiness in this account is partially a result of her relation to herself and to the outside world (Prager 1998). She acknowledges that - at age eighty - the happiest times of her life are in the past, and that as she and her family have grown older, this happiness has withered. However, whilst she may not be as happy in the present as she was in the past, she is still able to come to terms with the idea that parts of her life have been happy. Thus, this again may be one narrative through which older people make sense of their past and present.

Whether each of these accounts are imagined 'fantasies' about the past or a retelling of actual historical events is immaterial here; rather, what is noteworthy is that such reflections on a 'happy' past may constitute one culturally dominant discourse or narrative in which older people position themselves in order to make sense of their past and present lives (Jedlowski 2001). Furthermore, this also resonates with Jeffrey Prager's (1998) claim that memories are the result of an individual's relation to their self and to the outside world. Older people - such as these respondents aged sixty and above - are likely to relate to their selves and to the world in ways distinct from that of younger people (see Phillipson 1998; Arber, Davidson and Ginn 2003) as they have a larger bank of past experiences and memories from which to draw, as well as being closer to the ends of their lives. Being members of the same generation, they are likely to have experienced similar historical and social circumstances, and could therefore be said to share certain dispositions, preferences and a common habitus, which organize the way in which they see the world (Bourdieu 1977; Misztal 2003). Older people can also be said to have a 'past-situated social identity' (Dowd 1986: 154). That is, for them, 'the world has changed so significantly, it is no longer a world that is recognizable to the aged or one in which they feel "at home".' (Dowd 1986: 154). They are thus regarded as 'strangers' to others; because they do not necessarily feel at ease in the world, they are considered to be 'oldfashioned' as they continue to engage with outmoded preferences, ways of life and cultural practices (Dowd 1986). Therefore, it may be that if older people feel that they have less of a place in 'contemporary cultural experience' (Dowd 1986: 154) they are also less likely to draw happiness 
from the present than they would do from the past. Therefore, drawing upon the narrative outlined here, whereby life was deemed happier in the past than in the present, is one way in which such individuals may articulate their memories and their happiness as well as their relationship with the social world.

\section{Happiness can be gained from reminiscing about the past}

The second theme of the article is the idea that happiness can be gained from reminiscing about the past. This constitutes an original contribution to the sociological studies of both memory and happiness, as this notion is largely unexplored across the discipline.

A large number of interview participants of a range of ages expressed this idea. For instance, Gillian feels that good memories are 'important to your wellbeing':

(Gillian, 46): I get a lot of pleasure from reminiscing. And that's why I said it's experiences that make you happy. Because it's those things that stick with you, you know, the happy times that stick with you... good memories are important to your wellbeing. [...] I sometimes think about people I used to hang around with when I was in my early twenties ... I'm very accepting of every decade and how it changes, and you know, how your priorities change, like I wouldn't wanna be going out clubbing all the time now, do you know what I mean? But you sometimes look back and think oh, I had less worries, I had less responsibilities, and weren't times good when you could just go and blow all your money on nights out and stuff... so yeah, I tend to think about the past a lot... good experiences, yeah, if you reminisce on them, it can keep you happy. As I said, they're only memories, but they're there forever.

Gillian explains that whilst she does not necessarily wish for her present life to be the same as her past, she draws happiness from reflection upon her previous experiences. It can be inferred from this account that Gillian does not necessarily feel her past to be happier than her present, as the previous theme explores, but that thinking about good times that have passed allows her to experience a happier present.

Twenty-five-year-old respondent Nick makes the observation himself that people can become 'sentimental' about the past when they reach a certain age:

(Nick, 25): I find people get more sentimental as they get older, and they begin to appreciate things more. I think that's what... before, l'd like, go out, and have experiences and go 'oh this is fine', but now I look back on nights out and times with friends and I go 'this is great'. And sometimes I have nights out and I go 'I'll remember this night, this is brilliant', and I'm having a lot of that recently, and I think you need to have a little bit of age behind you... and I'm sure it'll get even more, you know, to appreciate things ... People get a lot of joy out of... people romanticise things, like you have a night out and think 'that was a brilliant night'... it probably wasn't that good at the time, but it's like you can feed off that, you know, by looking at photos... 
Nick's account suggests not only that he believes that older people are more likely to be nostalgic about the past, but also that he understands himself as being at an age where memories are increasingly important for happiness.

Lizzie describes how reflection on past memories are an important aspect of her relationship with her sister:

(Lizzie, 26): I get happiness from my relationship with my sister. Talking to her about different memories that we had when we were growing up, both happy and sad as well, it's just refreshing to know every once in a while that I'm not the only person who thinks like that. You know, she can remind me of things that happened when we were growing up as well, that I'd completely forgotten...

She feels that she is able to share memories with her sister that she would not necessarily be able to share with anybody else, as much of their childhood was shared. Furthermore, she is able to learn about early experiences from her sister that she may not have remembered, as her sister is older than she is. Her relationship with her sister offers an opportunity to learn about her own identity, family and childhood, and it is this that provides her with a sense of happiness.

Reminiscing about the past is something that can be done with the support of material objects such as videos and photographs (Zerubavel 1996), and the quote from Maureen below is one illustration of this. She talks about her childhood in her interview, and describes a DVD that she has acquired, containing scenes of past family events:

(Maureen, 80): I had a lovely childhood... I've even got a DVD of it, because my father had a cine camera and my cousin had it made into a DVD, and it's from the time we were children... you see all the family sitting on the beach, they were very happy times for everybody. It's lovely, seeing all your relatives on there... And you see all these people at the wedding... It's in black and white, and those hairstyles, and the old fashioned swimming hats that they used to wear [laughing], and those swimming costumes! Those were happy days. Yes, watching that brings back very happy memories... my dad was there, and my uncles were there, and my sister who has passed away... and my brother in his air force uniform... I'll show you a picture ...

Respondent gets up to show a number of old family photographs from her childhood.

During the interview, she expressed a great deal of happiness and pleasure in relation to being able to re-visit past events by watching the DVD. This was, at times, non-verbal, through smiling and laughter. Thus, not only were these events 'happy days' at the time of their occurrence, but the ability offered by the film to re-live them also provides Maureen with a sense of present happiness. This reflection also prompted her to show a number of old family photographs during the interview, the act of which was also a clear source of happiness (again, expressed through non-verbal displays such as smiling). The use of video and photographic images to capture and re-visit the past is becoming increasingly common (Zerubavel 1996), and Maureen's account demonstrates how such use of technology can also be a means of experiencing happiness. 
Therefore, it is evident from this section that reminiscing about or reflecting on the past is often understood as an act that can offer experiences of happiness and well-being. Why do people idealize or feel nostalgic for the past? It may be that this is one way in which people of all ages deal with lifecourse transitions. That is, that when people transition from one stage of their life to another (such as from childhood to adulthood, or from adulthood to old age, for example), their everyday experiences often undergo dramatic change (Pilcher 1995). It may be that they go from being independent and childless to having offspring and a mortgage to take care of, or they may go from full-time work to living on a pension. Changes in health and outlook often accompany these transitions, and the new experiences may seem foreign, strange and inferior. Thus, in order to grow accustomed to a new way of life after the departure of another, people may reflect on prior experience as happy, in order that they can maintain an acquaintance with their seemingly familiar previous life-stage. Nostalgia and engagement with the past may intensify further when people reach old age, as their feelings of ease with the contemporary world lessen, their engagement with its culture diminishes, and their 'past-situated social identity' emerges (Dowd 1986).

Indeed, both analytical sections here also highlight the ways in which people (particularly older ones) can position their happiness in the past, rather than in the present. This poses a major challenge to much of the work which has hitherto been undertaken on happiness. As explored above, Veenhoven (2011) suggests that current societal living conditions can have an effect on people's happiness. What we have seen here, though, is that people's happiness can be brought about by conditions or events that are no longer taking place, that occurred in the past. Although Veenhoven's claim cannot be dismissed - as much happiness is indeed experienced in response to present conditions - it can also be argued here that memories and reminiscence are used as 'technologies of the self' with which people can make themselves feel better about their lives. In other words, the act of reminiscing and reconnecting with the past is a technique that people perform on their own minds, 'so as to transform themselves in order to attain a certain state of happiness, purity, wisdom, perfection, or immortality.' (Foucault 1988: 18).

Work that has been done on the measurement of happiness can also be challenged, as much of this makes the implicit assumption that happiness is something that is experienced in the present. As acknowledged in the first half of the article, survey questions that capture happiness ask respondents about how they feel 'these days', or something else of a similar nature (see the 'Happiness and Sociology' section for the question wording). Such questions would be less able to cater for individuals who had experienced happiness during their lives in the past, but not in the present, but who nevertheless may feel that they had had a 'happy' life overall. Thus, what this paper has shown is that happiness may be experienced through a relation to the past, thus rendering it temporally complex. This is explored in more detail in the proceeding section.

\section{Concluding Comments}

Memories and past experiences play a clear role in the way in which people make sense of happiness. This paper has shown them to be of particular importance to older people, who reflect on earlier years of their lives as happier than the present, thus positioning their happiness in the past. Furthermore, the act of reminiscing about the past can also be a source of happiness and pleasure for adults of all ages. 
The findings drawn from this article have a number of implications for the ways in which happiness and memory are studied sociologically. In particular, they pose a challenge to the way in which scholars working in the area have theorized happiness. As highlighted at the end of the preceding section, measures of it are all based upon an assumption that it is happiness in the present that must be captured. This is undoubtedly a very important dimension of happiness to gather understandings of, as happiness is commonly articulated with reference to the present (and many authors have demonstrated this - see Layard 2011; Veenhoven 2011; Graham 2009, for example), but a deeper, richer picture of well-being could be achieved if one were - in addition to this - to account for the possibility that people's experiences of happiness have a strong temporal dimension, and can be positioned in the past or the future. That is, people's present experiences may not be inherently happy per se, but they may take happiness from reflection upon 'happy' events or periods from the past, or simply from the act of reminiscing. It is in this way that this happiness, made sense of via the 'remembering self' (Kahneman 2011), is qualitatively different from people's 'present', 'current' happiness - made sense of via either the 'experiencing' or 'remembering self' - that is being measured and monitored so widely.

This article also has implications for the theorization of the relationship between happiness and age. It is widely known that this relationship is U-shaped: that is, young and old people are happier than those in middle age (Blanchflower and Oswald 2007). This paper offers no support nor challenge to this finding, as it does not seek to uncover happiness levels across the life course; however, it does complement findings such as this, as it highlights a number of distinctive ways in which older people understand and perceive happiness as compared to younger people. Older people, because of their 'past situated social identity' (Dowd 1986) do not necessarily feel at ease in the world currently. This is because the cultures known to them in the past were quite different to that of today. They therefore draw more happiness from the past than from the present, and it is in this way that their present happiness is also past-situated. This happiness they draw from the past does not necessarily render their present lives unhappy however, as they gain happiness from reminiscence. Indeed, the act of reminiscence is a source of happiness for adults of all ages, as they seek a connection with previous, more familiar and comfortable stages of their lives, and it is this that allows them to remain acquainted with the 'known' aspects of their biographies. However, it is the past-situated identities of older people that lead them to heightened nostalgia and idealization of the past.

The link between happiness and time is thus an important one. As individuals move through the life course, each life stage can bring vastly different daily experiences. Idealization of or nostalgia for the past can be thought of as a 'technology of the self' (Foucault 1988) that adults of all ages employ to feel better about their lives as they move through life course transitions. They reflect upon experiences from prior stages of their lives, which they remember as being happy. Both time and age, then, must become key ideas in the growing subfield of sociology of happiness and wellbeing.

\section{Notes}

${ }^{1}$ Source of funding for the research.

\footnotetext{
${ }^{1}$ This research was undertaken as part of a PhD Studentship funded by the Economic and Social Research Council (2007-2010)
} 


\section{References}

ARBER, S Davidson, K and Ginn, J (2003) Gender and Ageing: Changing Roles and Relationships. Maidenhead: Open University Press.

BLANCHFLOWER, D G and Oswald, A (2007) 'Is Well-Being U-shaped Over the Life Cycle?' NBER Working Paper No. 12935.

BOURDIEU, P (1977) Outline of a Theory of Practice. Trans. R. Nice. Cambridge: Cambridge University Press. [doi://dx.doi.org/10.1017/СBO9780511812507]

CIESLIK, M (2013) 'Sociology and Making Sense of Happiness.' Paper presented at the British Sociological Association Annual Conference, London, April 3-5, 2013.

CSIKSZENTMIHALYI, M and Hunter, J (2003) 'Happiness in Everyday Life: The Uses of Experience Sampling.' Journal of Happiness Studies. Vol. 4, p.185-199.

[doi://dx.doi.org/10.1023/A:1024409732742]

DOWD, J (1986) The Old Person as Stranger in Marshall V W (Ed.) Later Life: The Social Psychology of Aging, Beverley Hills: Sage.

DURKHEIM, E ([1925] 1961) Moral Education. New York: Free Press.

DURKHEIM, E ([1897] 1951) Suicide. New York: Free Press.

EASTERLIN, R A (2001) 'Income and Happiness: Towards a Unified Theory.' The Economic Journal Vol. 111, p. 465-484. [doi://dx.doi.org/10.1111/1468-0297.00646]

EASTERLIN, R A (1974) Does Economic Growth Improve the Human Lot? Some Empirical Evidence in David P A (Ed.) Nations and Households in Economic Growth: Essays in Honour of Moses Abramovitz, London: Academic Press.

EYERMAN, R and Turner, B (1998) 'Outline of a theory of generations.' European Journal of Social Theory. Vol. 1, No. 1, p.91-106. [doi://dx.doi.org/10.1177/136843198001001007]

FOUCAULT, M. (1988). Technologies of the Self in Martin L H, Gutman, H \& Hutton, P H (Eds.) Technologies of the Self, London: Tavistock.

GRAHAM, C (2009) Happiness around the world: the paradox of happy peasants and miserable millionaires. Oxford: Oxford University Press.

HALBWACHS, M ([1926] 1950) The Collective Memory. Trans. F.J. and V.Y. Ditter. London: Harper Colophon Books. 
HYMAN, L (2011) Happy and you know it? A cultural exploration of people's experiences and perceptions of happiness. Unpublished PhD thesis. University of Surrey.

JEDLOWSKI, P (2001) 'Memory and Sociology: Themes and Issues.' Time and Society. Vol. 10, No. 1, p.29-44. [doi://dx.doi.org/10.1177/0961463X01010001002]

KAHNEMAN, D (2011) Thinking, Fast and Slow. London: Penguin.

KAHNEMAN, D, Krueger, A.B, Schkade, D.A, Schwarz, N and Stone, A.A (2004) 'A Survey Method for Characterizing Daily Life Experience: The Day Reconstruction Method.' Science. Vol. 306, No. 5072, p.1776-1780. [doi://dx.doi.org/10.1126/science.1103572]

LAYARD, R (2011) Happiness: Lessons from a New Science. London: Penguin

MANNHEIM, K (1972) Essays on the Sociology of Knowledge. London: Routledge.

MISZTAL, B (2003) Theories of Social Remembering. Maidenhead: Open University Press.

OFFICE FOR NATIONAL STATISTICS (2013) National Well-being [online]. [Accessed 16 April 2013]. Available from: <http://www.ons.gov.uk/ons/guide-method/user-guidance/well-being/index.html>.

OSWALD, A (1997) 'Happiness and Economic Performance.' The Economic Journal Vol. 107, p.18151831. [doi://dx.doi.org/10.1111/j.1468-0297.1997.tb00085.x]

PHILLIPSON, C (1998) Reconstructing Old Age: New Agendas in Social Theory and Practice. London: Sage.

PILCHER, J (1995) Age and Generation in Modern Britain. Oxford: Oxford University Press.

PRAGER, J (1998) Presenting the Past: Sociology and the Psychoanalysis of Misremembering. Cambridge MA: Harvard University Press.

RUBIN, H J and Rubin, I S (2005) Qualitative Interviewing: the art of hearing data. Thousand Oaks: Sage.

SCHWARTZ, B (2000) Abraham Lincoln and the Forge of National Memory. Chicago: Chicago University Press.

SELIGMAN, M E P (2002) Authentic Happiness: Using the New Positive Psychology to Realize your Potential for Lasting Fulfillment. New York: The Free Press.

SILVERMAN, D (2005) Doing Qualitative Research: A Practical Handbook. London: Sage.

STRAUSS, A L and Corbin, J (1990) Basics of Qualitative Research: Techniques and Procedures for Developing Grounded Theory. Thousand Oaks: Sage. 
VEENHOVEN, R (2011) Greater Happiness for a Greater Number: Is that possible? If so, how? in Sheldon K M, Kashdan T B \& Steger M F (Eds.) Designing Positive Psychology: Taking Stock and Moving Forward, New York: Oxford University Press.

[doi://dx.doi.org/10.1093/acprof:oso/9780195373585.003.0026]

ZERUBAVEL, E (1996) 'Social Memories: Steps to a Sociology of the Past.' Qualitative Sociology. Vol. 19, No. 3, p.283-299. 